\title{
First results of the German Barcode of Life (GBOL) - Myriapoda project: Cryptic lineages in German Stenotaenia linearis (Koch, I 835) (Chilopoda, Geophilomorpha)
}

\author{
Thomas Wesener', Karin Voigtländer², Peter Decker², \\ Jan Philip Oeyen', Jörg Spelda ${ }^{3}$, Norman Lindner ${ }^{4}$
}

I Zoologisches Forschungsmuseum Alexander Koenig, Leibniz Institute for Animal Biodiversity, Center for Taxonomy and Evolutionary Research (Section Myriapoda), Adenauerallee 160, 53113 Bonn, Germany 2 Senckenberg Museum of Natural History Görlitz, Am Museum 1, 02826 Görlitz, Germany 3 Bavarian State Collection of Zoology, Münchhausenstraße 21, 81247 Munich, Germany 4 Lazarusstraße 34, 04347 Leipzig, Germany

Corresponding author: Thomas Wesener (t.wesener@zfmk.de)

Academic editor: Ivan H. Tuf | Received 28 October 2014 | Accepted 15 May 2015 | Published 30 June 2015

http://zoobank.org/CD9AA03B-A43C-4D0A-B2A2-A6FF690470F9

Citation: Wesener T, Voigtländer K, Decker P, Oeyen JF, Spelda J, Lindner N (2015) First results of the German Barcode of Life (GBOL) - Myriapoda project: Cryptic lineages in German Stenotaenia linearis (Koch, 1835) (Chilopoda, Geophilomorpha). In: Tuf IH, Tajovský K (Eds) Proceedings of the $16^{\text {th }}$ International Congress of Myriapodology, Olomouc, Czech Republic. ZooKeys 510: 15-29. doi: 10.3897/zookeys.510.8852

\begin{abstract}
As part of the German Barcode of Life (GBOL) Myriapoda program, which aims to sequence the COI barcoding fragment for 2000 specimens of Germany's 200 myriapod species in the near future, 44 sequences of the centipede order Geophilomorpha are analyzed. The analyses are limited to the genera Geophilus Leach, 1814 and Stenotaenia Koch, 1847 and include a total of six species. A special focus is Stenotaenia, of which 19 specimens from southern, western and eastern Germany could be successfully sequenced. The Stenotaenia data shows the presence of three to four vastly different (13.7-16.7\% p-distance) lineages of the genus in Germany. At least two of the three lineages show a wide distribution across Germany, only the lineage including topotypes of $S$. linearis shows a more restricted distribution in southern Germany. In a maximum likelihood phylogenetic analysis the Italian species $S$. 'sorrentina' (Attems, 1903) groups with the different German S. linearis clades. The strongly different Stenotaenia linearis lineages within Germany, independent of geography, are a strong hint for the presence of additional, cryptic Stenotaenia species in Germany.
\end{abstract}

Copyright Thomas Wesener et al. This is an open access article distributed under the terms of the Creative Commons Attribution License (CC BY 4.0), which permits unrestricted use, distribution, and reproduction in any medium, provided the original author and source are credited. 


\section{Keywords}

Barcode, biodiversity, COI, cryptic diversity

\section{Introduction}

The German Barcode of Life - Myriapoda project aims to sequence part of the mitochondrial cytochrome $c$ oxidase subunit I gene known as the barcode fragment for all approximately 200 Myriapoda species in Germany (Voigtländer et al. 2011). Introduced species, mainly from greenhouses (Decker et al. 2014), will also be included. Myriapod barcoding is still in its infancy. While some studies incorporate COI data, this is mostly done on the species-level (e.g. Oeyen et al. 2014), and occasionally in genus-level studies (e.g. Stoev et al. 2010, Wesener et al. 2014). In Germany, a study of Bavarian myriapods (Spelda et al. 2011) pioneered research in this field.

Here, we show the preliminary results of one of the largest barcoding datasets compiled for centipedes of the order Geophilomorpha, with a special focus on the recently revised Stenotaenia Koch, 1847 (Bonato and Minelli 2008). Stenotaenia is distributed in Europe and the adjacent Mediterranean area and now includes 15 valid species. Stenotaenia linearis (Koch, 1835) is the type species of the genus, and the only species recorded from Germany (Voigtländer et al. 2011). After the resurrection of the genus in 2008, some redescriptions were undertaken (Dányi 2010), and the species $S$. linearis was recorded from Belgium for the first time (Lock 2009).

The taxonomic situation of the type species of Stenotaenia, S. linearis, is slightly confused, as the original Koch type specimens from Regensburg, Germany are apparently lost (Bonato and Minelli 2008). Seven species are currently synonymized under the name $S$. linearis (Bonato \& Minelli, 2014). Another four valid species, $S$. asiaeminoris (Verhoeff, 1898), S. giljarovi (Folkmanova, 1956), S. naxia (Verhoeff, 1901), and S. palaestina (Verhoeff, 1925), spanning the entire geographical range of the genus, are difficult to distinguish from S. linearis (see Bonato and Minelli 2008). A correct definition of $S$. linearis is therefore a crucial necessity for any further taxonomic work in the genus.

Molecularly, little was done in Stenotaenia. One specimen of S. linearis was used for the Fauna Bavarica project (Spelda et al. 2011). Of other Stenotaenia species, only one sequence of Stenotaenia 'sorrentina' (Attems, 1903), a putative synonym (ICZN 2014) of Geophilus forficularius Fanzago, 1881, which was part of a recent phylogenetic study (Bonato et al. 2014) can be found. The discovery of unusually large genetic distances between different clades in German $S$. linearis, not found in any other German Geophilomorpha, and potentially independent of biogeography, prompted us to focus our attention on this species. In this study, the genetic distances in between German Stenotaenia linearis specimens are geographically analyzed and interpreted. 


\section{Material and methods}

\section{Specimen collection and preparation}

Specimens were determined and collected by the authors of the study by hand, and either directly or after a few days transferred to vials containing $95 \%$ undenatured ethanol. The vials contain an individual GBOL number with which the specimens can be connected to the accompanying data. After conservation the specimens were either sent to the GBOL facility at the Museum Koenig, Bonn, Germany (ZFMK) or to the corresponding laboratory at the Bavarian State collection of Zoology, Munich, Germany (ZSM). Upon arrival, all specimens were photographed (images will be uploaded to BOLD, http://www.boldsystems.org/), and a tissue sample was removed for DNA extraction. All specimens will later be stored as vouchers in $95 \%$ undenatured ethanol, either at the ZFMK, the SMNG (Senckenberg Museum für Naturkunde, Görlitz) or the ZSM (see Table 1). For this specific GBOL subproject, DNA extraction was attempted for more than 35 specimens of Geophilus and 24 Stenotaenia, all specimens from Germany.

\section{DNA extraction and sequencing}

At the ZFMK, DNA was extracted from the tissue samples using the BioSprint96 magnetic bead extractor by Qiagen (Germany). After the extraction, samples were outsourced for PCR and sequencing (BGI China). For PCR and sequencing, HCO/LCO primer pairs (Folmer et al. 1994) were utilized. Because of a low PCR and sequencing success (<50\%) for the Myriapoda, the degenerated primer pair HCOJJ/LCOJJ (Astrin and Stüben 2008) was used for further sequencing attempts, resulting in a much higher success rate $(>75 \%)$. At the ZSM, a tissue sample was removed from each specimen and transferred into 96 well plates for subsequent DNA extraction at the Canadian Center for DNA Barcoding (CCDB) where they were processed using standard barcoding protocols. All protocols for DNA extraction, PCR amplifications and Sanger Sequencing procedures are available online under: http://www.dnabarcoding.ca/pa/ge/research/protocols.for DNA. DNA was extracted from the whole voucher at the CCDB. All samples were PCR amplified with modified Folmer primers CLepFolF, and the same primers were employed for subsequent Sanger sequencing. All voucher information and the DNA barcode sequences, primer pairs and trace files were uploaded to BOLD (http:// www.boldsystems.org).

However, for more than five S. linearis and more than 10 Geophilus specimens no sequences could be obtained. Sequences were obtained for 19 Stenotaenia and 25 Geophilus specimens. Sequence identities were confirmed with BLAST searches (Altschul et al. 1997). All 44 new sequences were deposited in GenBank (see Table 1 for 


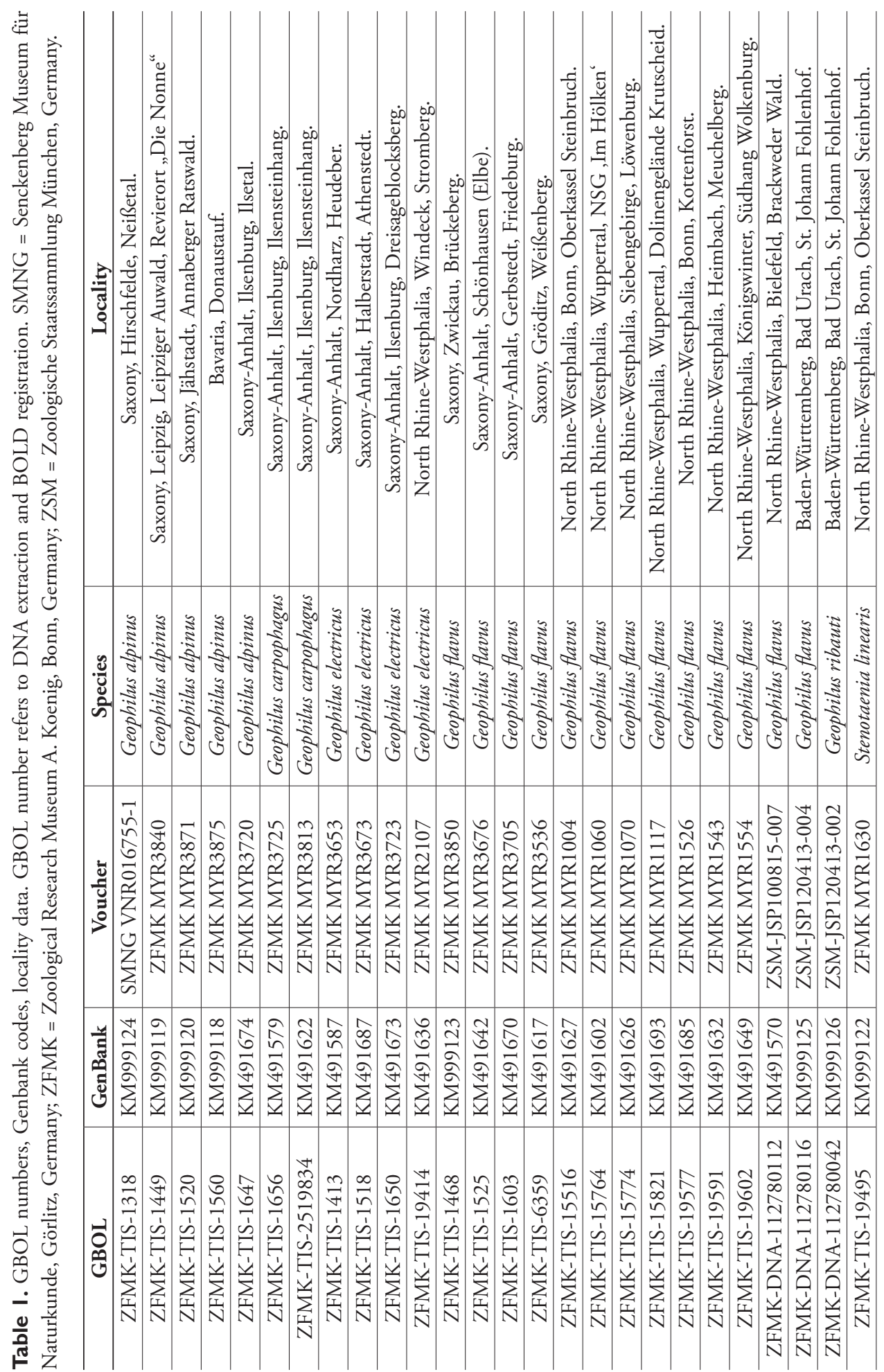




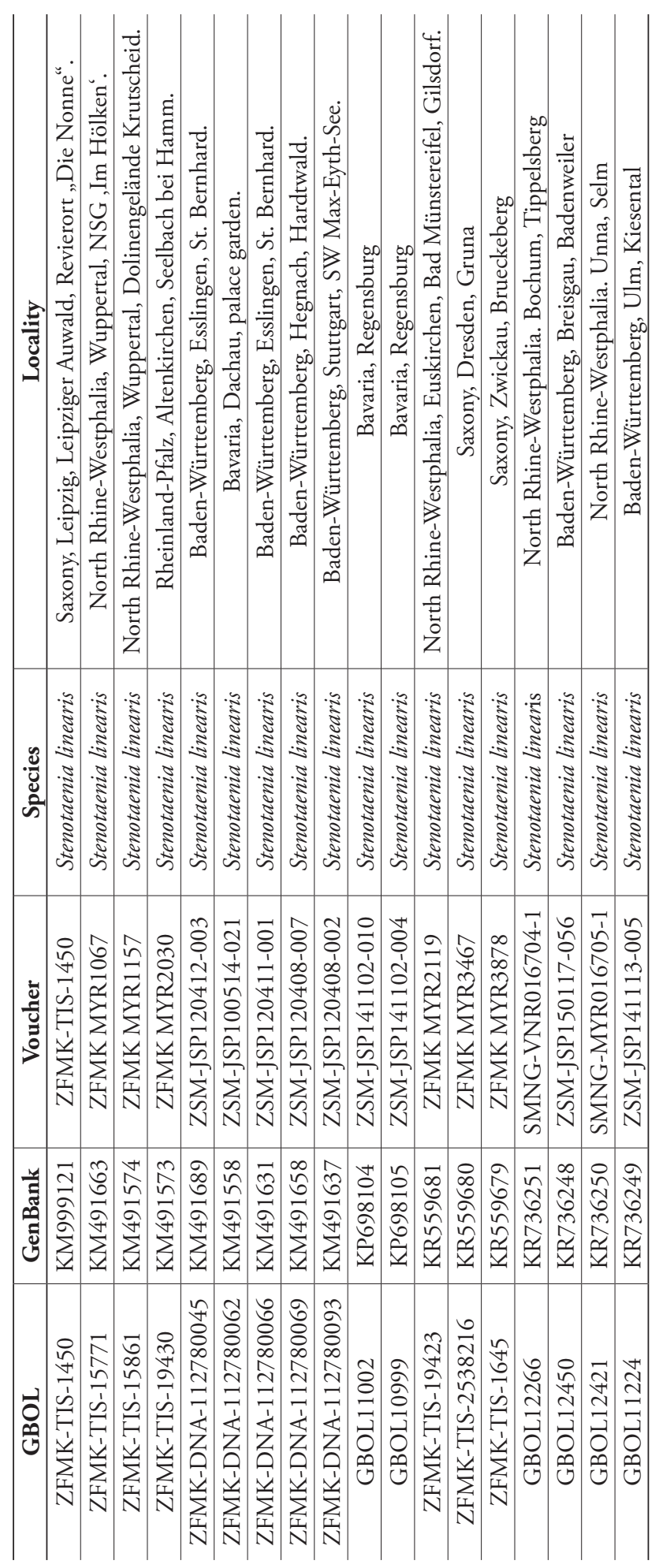


accession numbers). The only available COI sequence of Stenotaenia (KF569300.1), labelled as $S$. sorrentina, was added to the dataset. In order to rule-out the accidental amplification of nuclear copies of the mitochondrial COI gene, the whole dataset was translated into amino acids following the 'invertebrate' code in MEGA6 (Tamura et al. 2013); internal stop codons were absent in our dataset. There were a total of 658 positions in the final dataset, gaps were absent.

\section{Phylogenetic analysis}

Sequences were aligned by hand in Bioedit (Hall 1999). The final dataset included 45 nucleotide sequences with 658 positions ( 44 newly sequenced and the one of S. 'sorrentina' from GenBank). Phylogenetic analyses were conducted in MEGA6 (Tamura et al. 2013). A Modeltest, as implemented in MEGA6 (Tamura et al. 2013), was performed to find the best fitting maximum likelihood substitution model. Models with the lowest BIC scores (Bayesian Information Criterion) are considered to describe the best substitution pattern. Codon positions included were $1 s t+2 n d+3 r d+N o n c o d i n g$. Modeltest selected the Tamura-Nei model (Tamura and Nei 1993) with gamma distribution and invariant sites as best fitting model (nL -4245.19958, Invariant 0.55674, Gamma 1.176355, R 3.46, Freq A: 0.288843, T: 0.282885, C: 0.262778, G: 0.16546).

The evolutionary history was inferred by using the maximum likelihood method based on the selected Tamura-Nei model (Tamura and Nei 1993). The tree with the highest log likelihood (-4247.0145) is shown (Nei and Kumar 2000). The percentage of trees in which the associated taxa clustered together is shown next to the branches. Initial tree(s) for the heuristic search were obtained automatically by applying Neighbor-Join and BioNJ algorithms to a matrix of pairwise distances estimated using the Maximum Composite Likelihood (MCL) approach, and then selecting the topology with superior log likelihood value. A discrete Gamma distribution was used to model evolutionary rate differences among sites $(5$ categories $(+G$, parameter $=1.1347)$ ). The rate variation model allowed for some sites to be evolutionarily invariable $([+\mathrm{I}]$, $55.5093 \%$ sites). The tree is drawn to scale, with branch lengths measured in the number of substitutions per site.

\section{Distance analysis}

The number of pairwise base differences per site were calculated in MEGA6 (Tamura

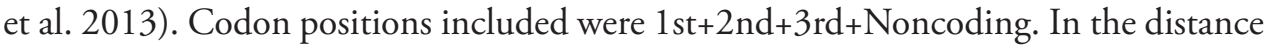
analysis, all positions containing 'N's were removed for each sequenced pair. There were a total of 658 positions in the final dataset. To further evaluate the divergence within the genera Geophilus and Stenotaenia, the frequency distribution of the pairwise intra- and inter-specific distances were analysed. 


\section{Results}

\section{Phylogenetic analysis}

Geophilus is not clearly separated from Stenotaenia in our analysis (Fig. 1). The basalmost node of the tree supports three monophyletic groups: G. flavus (de Geer, 1778), a species formerly separated in a different genus, Necrophloeophagus Newport, 1842, all other Geophilus, and Stenotaenia. However, the other Geophilus receive little statistical support (34\%). The monophyly of the individual Geophilus species, as well as the Stenotaenia lineages L1-L3, all receive 100\% bootstrap support (Fig. 1).

All 13 specimens of $G$. flavus show little genetic distance (0-2.4\%) to one another. Within the group containing the remaining Geophilus species, G. ribauti Brölemann, 1908, a species formerly treated as a member of the genus Brachygeophilus Brölemann, 1908 , is in a basal position to a weakly supported clade (64\% statistical support) including G. electricus (Linné, 1758), G. carpophagus Leach, 1814, and G. alpinus Meinert, 1870 . In this clade, G. electricus (100\% statistical support) is opposed to the sistertaxa G. carpophagus and G. alpinus (83\% statistical support). Inside G. electricus, the one specimen from western Germany is opposed to the three from Saxony-Anhalt (Table 1 and Fig. 1). G. alpinus is the only analyzed Geophilus species with widely separated intraspecific groups (Fig. 1). A basal trichotomy (Fig. 1) divides the five analyzed specimens into three groups that can not be separated geographically.

Within Stenotaenia, a basal trichotomy separates the specimens into (1) S. linearis L1, (2) S. 'sorrentina', and (3) the weakly supported (56\% bootstrap support) S. linearis L2 (including the topotypes) together with S. linearis L3 (Fig. 1). S. linearis L1 includes three specimens, one from Bonn, another from Euskirchen, both in western Germany and one from Leipzig in eastern Germany. S. linearis L2 contains a single specimen from Dachau, one close to Ulm, as well as two topotypes from Regensburg, all in southern Germany, while the majority (12) of analyzed German S. linearis specimens are recovered in S. linearis L3 (Fig. 1). The L3 group is divided into two clusters (L3a and b), one including seven specimens representing a single haplotype from seven different localities in western and eastern Germany, and the other one including five specimens also representing a single haplotype from four different localities (Esslingen, Hegnach, Badenweiler, and Stuttgart) in south-western Germany.

\section{Distance analysis}

The distance analysis shows a first cluster of intraspecific distances ranging from $0-2.8 \%$, with a $G$. electricus outlier at $4.9 \%$ (Fig. 2), a second cluster at $9.4-10.2 \%$, and a third cluster, which overlaps with the interspecific distances, at 13.7-16.7\%. Interspecific distances inside German Geophilus and Stenotaenia are high, varying from 16.3-22.0\%. The highest observed genetic distance is between Stenotaenia and Geophilus species (16.6-22.7\%), while the Geophilus species differ from one another by $17.2-21.7 \%$. 


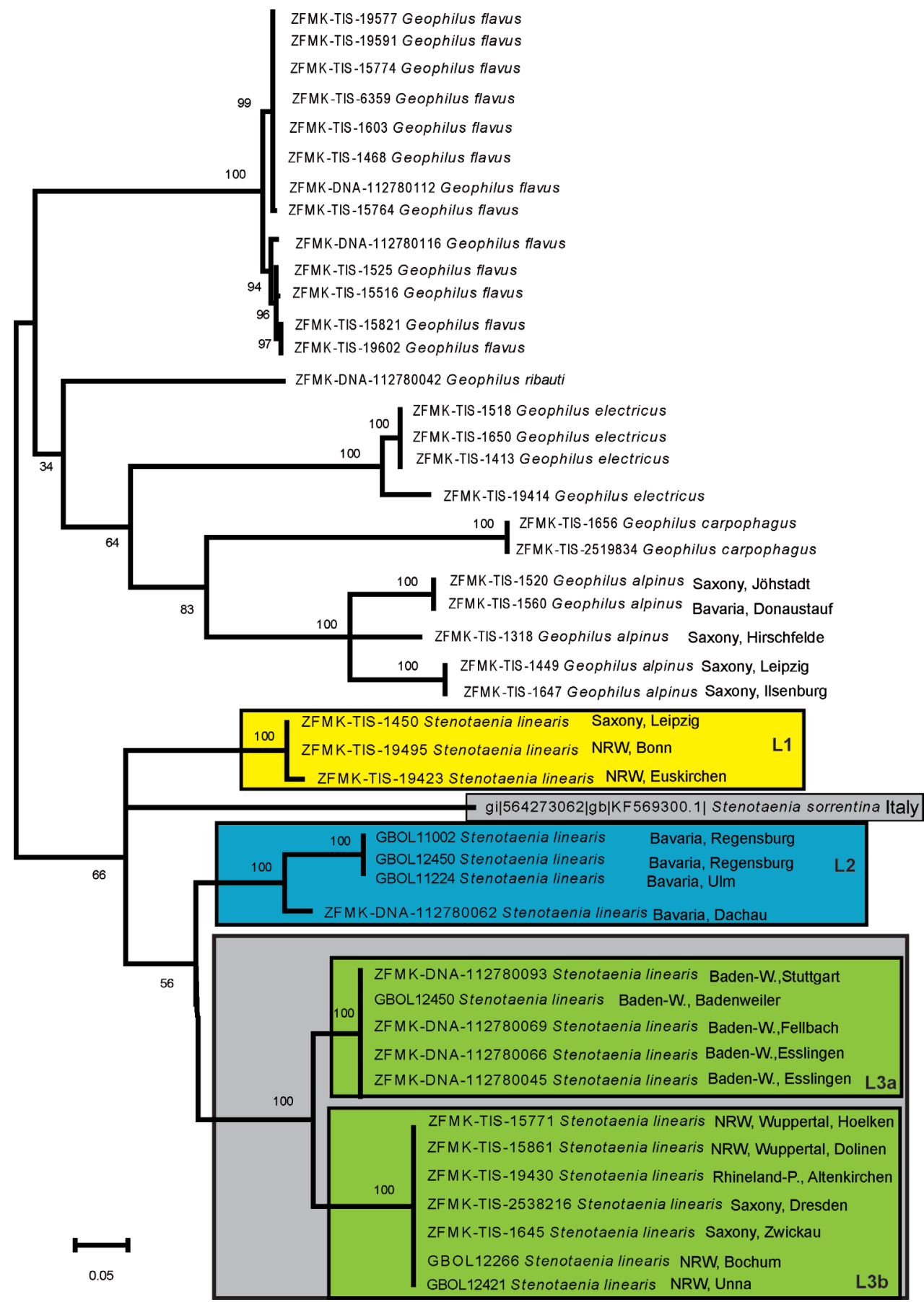

Figure I. Maximum likelihood tree, 1000 bootstrap replicates. L1-L3 = S. linearis lineages 1-3; NRW $=$ North Rhine-Westphalia; Baden-W = Baden-Württemberg. S. 'sorrentina' comes from GenBank and might refer to $S$. forficularis. For exact locality data, see Table 1. 


\section{Discussion}

\section{Distance analysis}

Clear intraspecific distances in German Geophilomorpha range from 0-5\% (Fig. 2). A potential barcoding gap, however, is filled by the relatively high intraspecific distances (Fig. 2) of G. alpinus and Stenotaenia L3 (9.4-10.2\% range). The genetic distances (13.7-16.7\%) between the different Stenotaenia lineages (L1, L2 \& L3) fall partly in the interspecific range of variation of the German Geophilomorpha (Fig. 2). The large interspecific distances (16.6-22.7\%) observed among German Geophilomorpha are an indication that all species can be easily separated using the COI barcode marker. The distance analysis is partly biased towards interspecific distances because only a few specimens per species were analyzed. To explain the high nucleotide variability, excluding cryptic species, the presence of the maternally inherited endosymbionts (Hurst et al. 2005), as well as the origin of the lineages from different glacial refugia (Babik et al. 2005) followed by a subsequent fusion to a single species, need to be checked.

\section{Three lineages of Stenotaenia in Germany}

The three German Stenotaenia lineages are only weakly geographically separated (Fig. 3). Stenotaenia L1 is represented in our dataset with one specimen from Bonn, one from Euskirchen, and a third specimen from Leipzig (Fig. 1), the first two localities are separated from the third by more than $400 \mathrm{~km}$ apart (Fig. 3). This clade can be described as the Stenotaenia specimen from central Germany. All three specimens show the same haplotype.

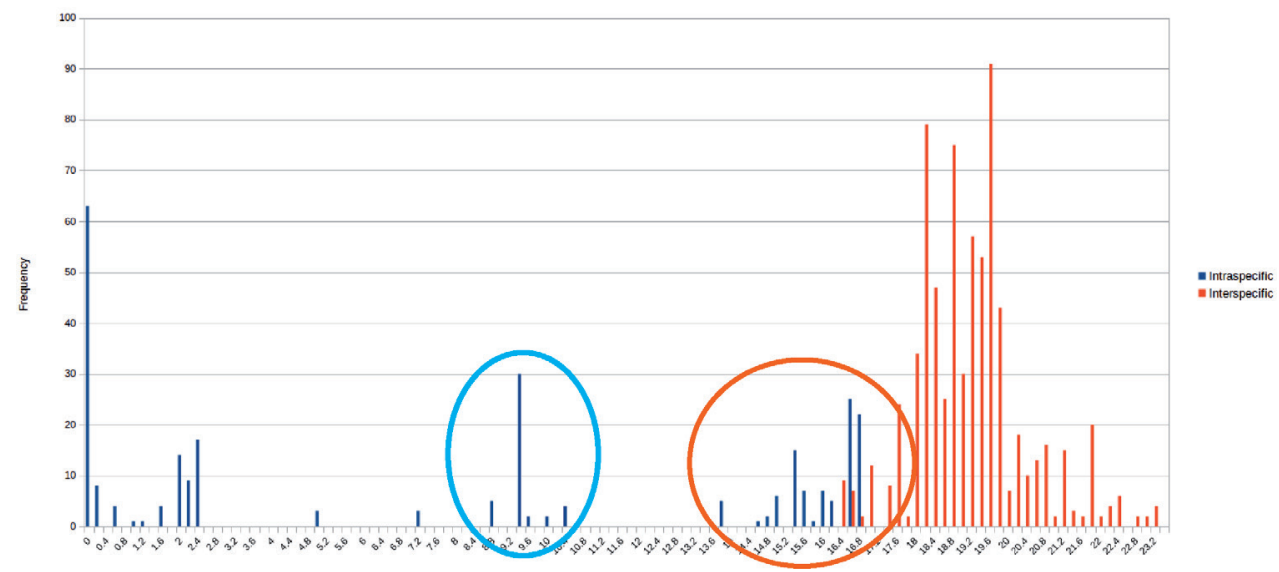

Figure 2. Frequency distribution of pairwise intraspecific (blue) and interspecific (red) distances. Blue circle $=$ intraspecific distances of $G$. alpinus and among $S$. linearis L3; Red circle = interspecific distances and distances between $S$. linearis lineages. Basic table see Suppl. material 1. 


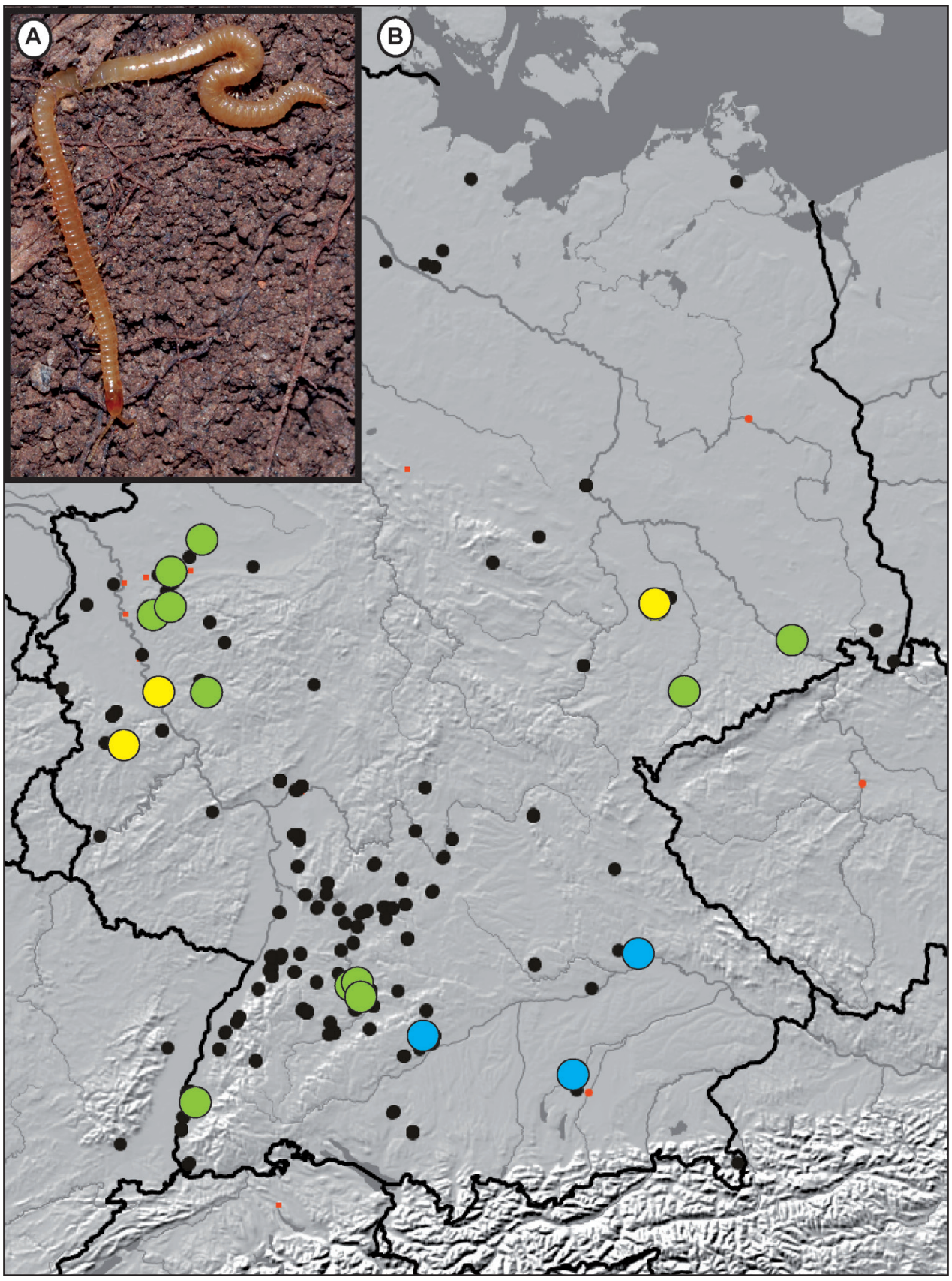

Figure 3. Map of $S$. linearis samples studied during GBOL (large dots), as well as other $S$. linearis records from Edaphobase, the ZSM and ZFMK collection (small dots, status 10.2014). Yellow = S. linearis L1; Blue $=S$. linearis $\mathrm{L} 2$; Green $=S$. linearis L3. (A) S. linearis in the field, photo: J. Spelda, specimen from Stuttgart-Hofen, Zuckerberg. 
Stenotaenia L2 represents topotypic material from Regensburg, a specimen from the Kiesental near Ulm, as well as a single specimen from Dachau in southern Germany. All three localities are more than $100 \mathrm{~km}$ apart but only the specimen from Dachau differs by $1.4 \%$. S. L2 differs significantly (13.7-16.7\%) from other German Stenotaenia. This clade might be characterised as of southeastern German origin along the Danube river system.

Both clades of lineage 3, one from western and eastern Germany (L3a), the other from SW Germany (L3b) show identical haplotypes, but differ from one another by $9.4 \%$ (Fig. 3). The intraspecific difference is similar to the differences observed in some Geophilus species (9.4-10.2\% in G. alpinus), but significantly larger than the differences observed in the widespread $G$. flavus $(0.2-2.4 \%)$, which often come from the exact same localities as the Stenotaenia specimens (Table 1).

Whether or not the apparent sympatric distribution of the three different lineages of Stenotaenia in Germany (Fig. 3) might have been influenced by human-induced introduction or dispersal is not known. Virtually all collection localities are close to human habitats, but differ strongly in their current direct exposure to human activities.

\section{Potential analysis problems and what we can learn for future work}

Such a large project faces a set of predictable technical problems, which can potentially cause wrong results.

Specimen collections: According to the main aim of the project (get approx. 10 specimens from at least five localities for each species to capture the estimated Germanwide COI variation), the different collectors preferred localities where they could find many myriapod specimens easily - a potential collection bias. The amount of successfully sequenced $S$. linearis specimens as well as $G$. alpinus specimens and their different positions and deep splits within the maximum likelihood tree (Fig. 1) tell us that a larger amount of specimens from many more regions in Germany (Fig. 3) would be a desirable object for future taxonomic and/or biogeographical studies on these species. Bergsten et al. (2012) showed that up to 70 individuals are required to sample $95 \%$ of the intraspecific variation.

Specimen determination: As done by Bonato et al. (2014) for all Geophilomorpha species, a data matrix of additional morphological characters, presumably morphometric characters, should be created for the detection of usable characters for determining the possible cryptic $S$. linearis taxa. However, it is not feasible to have such morphological studies as part of a large barcoding project like GBOL.

\section{Taxonomic implications}

Our analysis shows the importance of COI barcode data in the detection of taxonomic problems inside the centipede order Geophilomorpha. However, it also illustrates that 
barcode data alone does not clarify taxonomic problems. Only a thorough morphological study of the Stenotaenia species, including the types, plus the addition of nuclear markers, may be able to solve the complex picture of this genus.

As a result of the voucher-based barcoding effort, all analyzed specimens, and even their DNA extracts, are available for loan and should be incorporated into any future study of Stenotaenia.

\section{Acknowledgements}

Collection permits for natural protection areas were thankfully provided by the following people: H. Mölleken (Ressort Umweltschutz, Stadt Wuppertal), W. Wasch (Personal- und Organisationsamt, Bundesstadt Bonn), M. Ehling (Struktur- und Genehmigungsdirektion Nord, Rhineland-Palatine), F. Makiolczyk (Amt für Natur- und Landschaftsschutz, Rhein-Sieg-Kreis). T. Klug (ZFMK) provided assistance in collecting and determining the specimens. B. Rulik, J. Thormann, L. von der Mark form the GBOL-Team in Bonn and photographed, extracted and sequenced the ZFMK specimens, their invaluable help is greatly appreciated. M. Geiger assisted with the upload of the sequence data to GenBank. Special thanks go to M. Balke, F. Glaw, A. Hausmann, O. Hawlitschek, R. Melzer, J. Moriniere, I. Stöger, S. Schmidt for discussion, F. Ceseña, S. Friedrich, T. Lehmann, T. Meier, V. Svara, S. Swoboda and U. Biener-Miller (all ZSM) for sorting and preparing the ZSM samples. H. E. Wesener thankfully corrected the English of the manuscript. Two anonymous reviewers provided numerous comments that improved the quality of the here presented work.

This is a publication of the German Barcode of Life (GBOL) project of the Humboldt Ring, financed by the German Federal Ministry for Education and Research.

\section{References}

Altschul SF, Madden TL, Schäffer AA, Zhang J, Zhang Z, Miller W, Lipman DJ (1997) Gapped BLAST and PSI-BLAST: a new generation of protein database search programs. Nucleic Acids Research 25: 3389-3402. doi: 10.1093/nar/25.17.3389

Astrin JJ, Stüben PE (2008) Phylogeny in cryptic weevils: molecules, morphology and new genera of western Palaearctic Cryptorhynchinae (Coleoptera: Curculionidae). Invertebrate Systematics 22: 503-522. doi: 10.1071/IS07057

Attems C (1903) Synopsis der Geophiliden. Zoologische Jahrbücher, Abteilung für Systematik, Ökologie und Geographie der Tiere 18(2): 155-302.

Babik W, Branicki W, Crnobrnja-Isailovic J, Cogalniceanu D, Sas I, Olgun K, Poyarkov A, Gracia-Paris M, Arntzen JW (2005) Phylogeography of two European newt species - discordance between mtDNA and morphology. Molecular Ecology 14: 2475-2491. doi: 10.1111/j.1365-294X.2005.02605.x 
Bergsten J, Bilton DT, Fujisawa T, Elliott M, Monaghan MT, Balke M, Hendrich L, Geijer J, Herrmann J, Foster GN, Ribera I, Nilsson AN, Barraclough TG, Vogler AP (2012) The effect of geographic scale of sampling on DNA barcoding. Systematic Biology 61(5): 851-869. doi: 10.1093/sysbio/sys037

Bonato L, Minelli A (2008) Stenotaenia Koch, 1847: a hitherto unrecognized lineage of western Palaearctic centipedes with unusual diversity in body size and segment number (Chilopoda: Geophilidae). Zoological Journal of the Linnean Society 153: 253-286. doi: 10.1111/j.1096-3642.2008.00394.x

Bonato L, Minelli A (2014) Chilopoda Geophilomorpha of Europe: a revised list of species, with taxonomic and nomenclatorial notes. Zootaxa 3770: 1-136. doi: 10.11646/zootaxa.3770.1.1

Bonato L, Drago L, Murienne J (2014) Phylogeny of Geophilomorpha (Chilopoda) inferred from new morphological and molecular evidence. Cladistics 30(5): 485-507. doi: $10.1111 /$ cla. 12060

Brölemann HW (1908) La haute Vallée de la Neste (Myriapodes). Bulletin de la Société d'Histoire Naturelle de Toulouse 41: 57-67.

Dányi L (2010) A Moesian geophilomorph (Myriapoda: Chilopoda) species from the Carpathians: Review and redescription of Stenotaenia rhodopensis (Kaczmarek, 1970). Biologia Bratislava 65(6): 1028-1033. doi: 10.2478/s11756-010-0116-5

Decker P, Reip HS, Voigtländer K (2014) Millipedes and Centipedes in German greenhouses (Myriapoda: Diplopoda, Chilopoda). Biodiversity Data Journal 2: e1066. doi: 10.3897/ BDJ.2.e1066

de Geer C (1778) Neuvieme Memoire - Des Cloportes, Des Scolopendres \& Des Jules. In: Mémoires pour servir à l'histoire des insectes, Tome VII. P. Hesselberg, Stockholm, $\mathrm{VI}+950 \mathrm{pp}$.

Fanzago F (1881) Ein neuer italienischer Geophilus. Zoologischer Anzeiger 4: 378-379.

Folkmanova B (1956) On new forms of Geophilomorpha from southern provinces of U.S.S.R. to the knowledge of the Myriapoda of U.S.S.R. Zoologicheskii Zhurnal 35: 1633-1646. [In Russian]

Folmer O, Black M, Hoeh W, Lutz R, Vrijenhoek R (1994) DNA primers for amplification of mitochondrial cytochrome c oxidase subunit I from diverse metazoan invertebrates. Molecular Marine Biology and Biotechnology 3(5): 294-299.

Hall TA (1999) BioEdit: a user-friendly biological sequence alignment editor and analysis program for Windows 95/98/NT. Nucleic Acid Science 41: 95-98.

Hurst GDD, Jiggins FM (2005) Problems with mitochondrial DNA as marker in population, phylogeographic and phylogenetic studies: the effects of inherited symbionts. Proceedings of the Royal British Society 272: 1525-1534. doi: 10.1098/rspb.2005.3056

ICZN (2014) Opinion 2335: Geophilus linearis CL Koch, 1835 (currently Stenotaenia linearis; Chilopoda): specific name conserved and Geophilus sorrentinus (currently Stenotaenia sorrentina; Chilopoda) Attems, 1903: specific name not conserved. Bulletin of Zoological Nomenclature 71(2): 138-140.

Koch CL (1835) Deutschlands Crustaceen, Myriapoden und Arachniden. In: Herrich-Schäffer GAW (Ed.) Deutschlands Insecten. Pustet, Regensburg, 136-190. 
Leach WE (1814) Crustaceology. In: Brewster D (Ed.) The Edinburgh Encyclopaedia. Blackwood, Edinburgh 7(2): 383-437.

Lock K (2009) Stenotaenia linearis (C. L. Koch 1835): an expected species new to the Belgian fauna (Myriapoda Chilopoda). Bulletin de la Société Royale Belge des Electriciens 145: $114-116$.

Meinert F (1870) Myriapoda Musaei Hauniensis. Bitrag til Myriapodernes morphologi og systematik. I. Geophile. Naturhistorisk Tidsskrift (3) 7: 1-128.

Nei M, Kumar M (2000) Molecular evolution and phylogenetics. Oxford University Press, Oxford.

Oeyen JP, Funke S, Böhme W, Wesener T (2014) The Evolutionary History of the Rediscovered Austrian Population of the Giant Centipede Scolopendra cingulata Latreille, 1829 (Chilopoda, Scolopendromorpha). PLoS ONE 9(9): 1-11. doi: 10.1371/journal. pone. 0108650

Spelda J, Reip HS, Oliveira Biener U, Melzer RR (2011) Barcoding Fauna Bavarica: Myriapo$\mathrm{da}$ - a contribution to DNA sequence-based identifications of centipedes and millipedes (Chilopoda, Diplopoda). ZooKeys 115: 123-139. doi: 10.3897/zookeys.156.2176

Stoev P, Akkari N, Zapparoli M, Porco D, Enghoff H, Edgecombe GD, Georgiev T, Penev L (2010) The centipede genus Eupolybothrus Verhoeff, 1907 (Chilopoda: Lithobiomorpha: Lithobiidae) in North Africa, a cybertaxonomic revision, with a key to all species in the genus and the first use of DNA barcoding for the group. ZooKeys 50: 29-77. doi: 10.3897/ zookeys. 50.504

Tamura K, Nei M (1993) Estimation of the number of nucleotide substitutions in the control region of mitochondrial DNA in humans and chimpanzees. Molecular Biology and Evolution 10: 512-526.

Tamura K, Stecher G, Peterson D, Filipski A, Kumar S (2013) MEGA6: Molecular Evolutionary Genetics Analysis version 6.0. Molecular Biology and Evolution 30: 2725-2729. doi: $10.1093 / \mathrm{molbev} / \mathrm{mst} 197$

Verhoeff KW (1898) Beiträge zur Kenntniss paläarktischer Myriopoden. VI. Aufsatz: Ueber paläarktische Geophiliden. Archiv für Naturgeschichte 64(1): 335-362.

Verhoeff KW (1901) Zur vergleichenden Morphologie, Systematik und Geographie der Chilopoden. Beiträge zur Kenntnis paläarktischer Myriopoden XVI. Nova acta Academiae Caesareae Leopoldino-Carolinae Germanicae Naturae Curiosorum 77: 369-465.

Verhoeff KW (1925) Mediterrane Chilopoden und Notiz zur Periodomorphose der Juliden. Zoologischer Anzeiger 64(3-4): 63-80.

Voigtländer K, Reip HS, Decker P, Spelda J (2011) Critical reflections on German Red Lists of endangered myriapod species (Chilopoda, Diplopoda) (with species list for Germany). In: Mesibov R, Short M (Eds) Proceedings of the 15th International Congress of Myriapodology, 18-22 July 2011, Brisbane, Australia. International Journal of Myriapodology 6: 85-105. doi: 10.3897/ijm.6.2175

Wesener T, Le DMT, Loria SF (2014) Integrative revision of the giant pill-millipede genus Sphaeromimus from Madagascar, with the description of seven new species (Diplopoda, Sphaerotheriida, Arthrosphaeridae). ZooKeys 414: 67-107. doi: 10.3897/zookeys.414.7730 


\section{Supplementary material I}

Table. Estimates of Evolutionary Divergence between Sequences

Authors: Thomas Wesener, Karin Voigtländer, Peter Decker, Jan Philip Oeyen, Jörg Spelda, Norman Lindner

Data type: Measurement

Explanation note: The number of base differences per site from between sequences are shown. The analysis involved 45 nucleotide sequences. Codon positions included were $1 s t+2 n d+3 r d+$ Noncoding. All ambiguous positions were removed for each sequence pair. There were a total of 658 positions in the final dataset. Evolutionary analyses were conducted in MEGA6.

Copyright notice: This dataset is made available under the Open Database License (http://opendatacommons.org/licenses/odbl/1.0/). The Open Database License (ODbL) is a license agreement intended to allow users to freely share, modify, and use this Dataset while maintaining this same freedom for others, provided that the original source and author(s) are credited. 